\title{
ARTICLE
}

\section{NADPH ameliorates MPTP-induced dopaminergic neurodegeneration through inhibiting p38MAPK activation}

\author{
Jing-si Zhou ${ }^{1}$, Zhou Zhu ${ }^{1}$, Feng $\mathrm{Wu}^{1,2}$, Ying Zhou ${ }^{1}$, Rui Sheng ${ }^{1}$, Jun-chao $\mathrm{Wu}^{1}$ and Zheng-hong Qin ${ }^{1}$
}

\begin{abstract}
Parkinson's disease (PD) is the second most common neurodegenerative disorder characterized by the selective loss of dopaminergic neurons in substantia nigra pars compacta ( $\mathrm{SNpc}$ ). Although the pathogenic mechanism underlying PD remains largely unknown, decreased nigral glutathione (GSH) in postmortem brains of PD patients supports the presence of oxidative stress in PD. We found that Nicotinamide adenine dinucleotide phosphate (NADPH), which is important for maintaining the level of GSH, protected dopaminergic (DA) neurons from neurotoxicity of MPTP/MPP ${ }^{+}$. In the present study, NADPH prevented DA neurons from MPTP toxicity with increased GSH and decreased reactive oxygen species (ROS) levels in the ventral midbrain of mice, and improved motor activity. Our present results demonstrated that NADPH inhibited the phosphorylation of p38MAPK, decreased the level of TP53 protein, and inhibited TP53 nuclear translocation in DA neurons of SNpc and in MES23.5 cells. Furthermore, NADPH decreased the protein level of TP53 target gene, Bax, cleavage of PARP, and nuclei condensation. Taken together, NADPH abrogated MPTP-induced p38MAPK phosphorylation, TP53 nuclear translocation, and Bax induction, and finally, MPTP/MPP ${ }^{+}$induced apoptosis of DA neurons. This study suggests that NADPH may be a novel therapeutic candidate for PD.
\end{abstract}

Keywords: NADPH; PD; MPTP; ROS; P-p38MAPK; TP53

Acta Pharmacologica Sinica (2019) 40:180-191; https://doi.org/10.1038/s41401-018-0003-0

\section{INTRODUCTION}

Parkinson's disease (PD) is recognized as the second most common neurodegenerative disorder [1], in which progressive loss of midbrain dopaminergic (DA) neurons gives rise to characteristic motor disturbances [2]. Although the etiology of $\mathrm{PD}$ remains elusive, the pathogenesis is believed to be associated with glutathione (GSH) depletion-induced oxidative stress [3], mitochondrial dysfunction [4], activation of the apoptotic cascade [5], and so on.

It has been reported that there is a drastic depletion in GSH within the substantia nigra pars compacta (SNpc) of PD patients [6]. Moreover, research in the recent years has indicated that GSH depletion in DA neurons is one of the main pathogenic mechanisms of PD, as it makes DA neurons more vulnerable to oxidative injury [7]. The decrease in GSH level in postmortem brains of PD patients supports the presence of oxidative stress [8], which triggers a cascade of events leading to the death of DA neurons in PD [9].

Nicotinamide adenine dinucleotide phosphate (NADPH) is involved in a variety of antioxidant systems [10], allows the regeneration of GSH which would protect against the toxicity of reactive oxygen species (ROS) [11]. The ratio of NADPH/NADP+ is mainly determined by the pentose phosphate pathway [12], NADP-isocitrate dehydrogenase [13] and decarboxylating malic enzyme [14]. Pentose phosphate pathway is a main source of
NADPH [15]. However, disruption of pentose phosphate pathway in PD has also been found [16]. Thus, it is rational to study if supplementation of exogenous NADPH could have a neuroprotective effect in PD models. Our previous study has observed the protective effects of NADPH in oxygen and glucose deprivation/ reoxygenation (OGD/R)-induced elevation of ROS, reduction of $\mathrm{GSH}$, and dysfunction of mitochondria in a mouse model of ischemic stroke [17]. Therefore, we hypothesized that supplementation of NADPH might protect DA neurons from oxidative damage.

\section{MATERIALS AND METHODS}

Animal grouping and treatment

Adult male C57BL/6 mice, weighing 25-30 g, were purchased from Vital River (Beijing, China). All animals were used in accordance with the institutional guidelines for animal use and care, and the study protocol was approved by the ethical committee of Soochow University. Animals were randomly divided into 5 groups, 15 mice in each group. Mice were housed in cages and kept in a room maintained at a constant temperature of $22^{\circ} \mathrm{C}$, $40-70 \%$ humidity, and a 12/12 h light-dark cycle. The MPTP group was given 1-methyl-4-phenyl-1,2,3,6-tetrahydropyridine (MPTP, 30 $\mathrm{mg} / \mathrm{kg}$, M0896, Sigma-Aldrich, St. Louis, MO) intraperitoneally once a day for 5 consecutive days, and the therapeutic groups

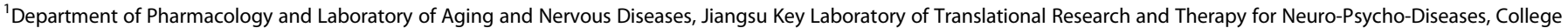

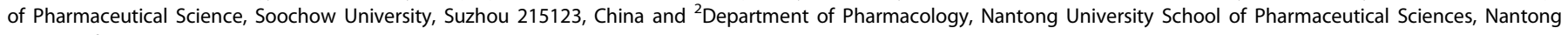
226001, China

Correspondence: Zheng-hong Qin (qinzhenhong@suda.edu.cn)

These authors contributed equally: Jing-si Zhou, Zhou Zhu.

Received: 25 August 2017 Revised: 15 January 2018 Accepted: 15 January 2018

Published online: 16 May 2018 
were intraperitoneally injected with different doses of NADPH (Roche, $L=2.5 \mathrm{mg} / \mathrm{kg}, M=5 \mathrm{mg} / \mathrm{kg}, H=10 \mathrm{mg} / \mathrm{kg}$ ) $2 \mathrm{~h}$ after MPTP injection in the first 5 days and twice a day in the next 16 days. Meanwhile, saline was injected as vehicle to the control mice.

\section{Immunohistochemistry}

After NAPDH treatment for 21 days, mice were anesthetized with $4 \%$ sodium pentobarbital and then perfused with ice-cooled 0.01 M phosphate-buffered saline (PBS) and 4\% paraformaldehyde sequentially. Following decapitation, the brain was immersed in $4 \%$ paraformaldehyde for $6 \mathrm{~h}$ and then dehydrated with gradient sucrose solutions $(20 \%, 30 \%)$ overnight. Striatum and midbrain were cut into serial sections at $40 \mu \mathrm{m}$ with a cryostat microtome (Leica CM1950; Leica, Wetzlar, Germany). Free-floating sections were blocked with $5 \%$ horse serum containing $0.5 \%$ Triton X-100 and incubated with primary antibodies against tyrosine hydroxylase (THase, 1:2000, T1299, Sigma-Aldrich, St. Louis, MO), followed by biotin-conjugated anti-mouse secondary antibody (1:500, Vector Laboratories, Burlingame, CA). The avidin-biotin complex $(A B C)$ method was used to detect antigen signal with $A B C$ Elite kit (1:100, Vector Laboratories, Burlingame, $C A)$ and 3,3'diaminobenzidine tetrachloride (DAB, Sigma-Aldrich, St. Louis, MO) was used to visualize the final product. The number of DA neurons in the SN was estimated by counting THase-positive neurons from every four consecutive sections. The number of THase-positive neurons and THase-positive optical density of striatum were normalized to control mice.

\section{Cell culture}

MES23.5 cells, provided by Professor Wei-Dong Le (Baylor College of Medicine, TX), were cultured in DMEM/F12 (Gibco) with 5\% fetal bovine serum (Gibco) and $1 \%$ insulin-transferrin-selenium solution (100X) (Gibco) in $5 \% \mathrm{CO}_{2}$ at $37^{\circ} \mathrm{C}$. SH-SY5Y cells were cultured in DMEM/F12 (Gibco) with 10\% fetal bovine serum (Gibco) in $5 \% \mathrm{CO}_{2}$ at $37^{\circ} \mathrm{C}$. For experiments, MES23.5 cells were seeded in plastic flasks at an appropriate density as described correspondingly. Then, the cells were pretreated with NADPH $10 \mu \mathrm{M}$ (ST360, Beyotime, Nantong, China) for $1 \mathrm{~h}$ before 1-methyl-4phenylpyridinium $\left(\mathrm{MPP}^{+}, \mathrm{D} 048\right.$, Sigma-Aldrich, St. Louis, MO) $200 \mu \mathrm{M}$ treatment.

\section{Cell viability assay}

MES23.5 cells were seeded onto a 96-well plate at a density of $5 \times$ $10^{3}$ cells per well. After pretreated with $\operatorname{NADPH}(5,10$, and $20 \mu \mathrm{M})$ for $1 \mathrm{~h}$, the cells were exposed to $200 \mu \mathrm{M} \mathrm{MPP}^{+}$for $24 \mathrm{~h}$. SH-SY5Y cells were seeded in a 96-well plate at a density of $10^{4}$ cells per well. The cells were exposed to $1 \mathrm{mM} \mathrm{MPP}^{+}$for $24 \mathrm{~h}$ after the pretreatment with $\operatorname{NADPH}(50,100$, and $200 \mu \mathrm{M})$ for $1 \mathrm{~h}$. Then, the cells were incubated with thiazolyl blue tetrazolium bromide (MTT, Sigma, $5 \mathrm{mg} / \mathrm{ml}$ ) at $37^{\circ} \mathrm{C}$ for $4 \mathrm{~h}$ in dark. Finally, the cell viability was measured by reading optical density at $490 \mathrm{~nm}$ with a microplate reader.

Western blot analysis

After decapitation, ventral midbrain that contains the SNpc and striatum were dissected as followed in The Mouse Brain in Stereotaxic Coordinates (Academic Press, 2nd edn by George Paxinos et al.). The tissues were homogenized with the lysis buffer containing Tris- $\mathrm{HCl}(\mathrm{pH} 7.4) 10 \mathrm{mM}, \mathrm{NaCl} 150 \mathrm{mM}, 1 \%$ Triton X-100, $1 \%$ sodium dexoxycholate, $0.1 \%$ polyacrylamide gel electrophoresis (SDS), edetic acid $5 \mathrm{mM}, 1$ protease inhibitor cocktail tablet (Roche), and 1 phosphotase inhibitor cocktail tablet (Roche)/10 ml. The lysates were then centrifuged at $12,000 \mathrm{rpm}$ for $15 \mathrm{~min}$ at $4{ }^{\circ} \mathrm{C}$ and the supernatants were used as the total cell lysates. Meanwhile, MES23.5 cells were seeded in a 6-well plate at a density of $5 \times 10^{5}$ cells per well. After the pretreatment with $10 \mu \mathrm{M}$ NADPH or $1 \mu \mathrm{M}$ SB203580 (S1863, Beyotime) for $1 \mathrm{~h}$ and followed exposure to $\mathrm{MPP}^{+}$for $12 \mathrm{~h}$, the cells were harvested and lysed in this lysis buffer. After centrifugation at $12,000 \mathrm{rpm}$ for $15 \mathrm{~min}$ at $4^{\circ}$ $C$, protein concentration was determined with BCA protein assay kit (T9300A, Takara Bio, Shiga, Japan). The protein samples were separated on $8-12 \%$ SDS-PAGE and then transferred to $0.45 \mu \mathrm{m}$ NC membranes. The membrane was incubated with $5 \%$ non-fat milk for $1 \mathrm{~h}$ at room temperature and then incubated with the primary antibodies against mouse anti-THase (1:5000; SigmaAldrich, T1299), rabbit anti-Bax (1:200; Santa Cruz, SC-526), mouse anti-TP53 (1:1000; Cell Signaling, 2524), rabbit anti-p-p38MAPK (1:1000; Cell Signaling, 4511), mouse anti-p38MAPK (1:500; Santa Cruz, SC-7972), mouse anti-extracellular signal regulated kinase (ERK1/2, 1:200; Santa Cruz, SC-3012), rabbit anti-p-ERK1/2 (1:2000; Cell Signaling, 4370), mouse anti-c-Jun N-terminal kinase JNK (1:500; Santa Cruz, SC-6254), rabbit anti-PARP (1:1000; Cell Signaling, 9532), rabbit anti-Lamin B1 (1:5000; Abcam, ab133741), mouse anti-GAPDH (1:5000; Sigma-Aldrich, SAB2100894), and mouse anti- $\beta$-actin (1:10000; Sigma-Aldrich, A5441) overnight at $4{ }^{\circ} \mathrm{C}$. After incubation with fluorescent secondary antibodies (1:10000; LI-COR Biosciences, anti-Mouse 926-32212; anti-Rabbit 926-32213) for $2 \mathrm{~h}$ at room temperature, the protein was detected with Odyssey Two-Color Infrared Imaging System (LI-COR, Linclon, NE). The proteins were analyzed with ImageJ and normalized to the loading control ( $\beta$-actin).

Measurement of NADPH and GSH levels

The ventral midbrain was dissected as previously mentioned. The levels of NADPH and GSH in midbrain were determined with the EnzyChrom NADP ${ }^{+} /$NADPH assay kit (BioAssay Systems, E2ND002, CA) and the GSH kit (Beyotime) following the manufacturer's instructions.

Reactive oxygen species (ROS) assay

After incubated with primary antibody against THase and fluorescent antibody as described in immunohistochemistry section, the midbrain sections were incubated with $10 \mu \mathrm{M}$ dihydroethidium (DHE, S0063, Beyotime) in $0.01 \mathrm{M}$ PBS for 30 min in dark at room temperature. Then, the brain sections were washed in 0.01 M PBS twice and dehydrated in a series of graded ethanol. Fluorescence intensity was measured with a laser confocal microscopy after the brain sections were mounted onto microslide and cover-slipped. Meanwhile, MES23.5 cells were seeded in a 24-well plate at a density of $4 \times 10^{4}$ cells per well. The cells were pretreated with $10 \mu \mathrm{M} N \mathrm{NADPH}$ or $0.5 \mathrm{mM} \mathrm{N}$-acetyl-Lcysteine (NAC, A9165, Sigma-Aldrich, St. Louis, MO) for $1 \mathrm{~h}$ and then exposed to $200 \mu \mathrm{M} \mathrm{MPP}{ }^{+}$for $12 \mathrm{~h}$. Then, the cells were incubated with $2 \mu \mathrm{M}$ DHE for $30 \mathrm{~min}$ in dark at $37^{\circ} \mathrm{C}$. Finally, the fluorescence intensity was measured with a laser confocal microscopy.

Hoechst 33342 staining and counting condensed nuclei Nuclear staining with fluorescent dyes Hoechst 33342 (Yuanye, Shanghai, China) was used to determine cell apoptosis according to a previous protocol. Briefly, MES23.5 cells were seeded in a 12well plate at a density of $8 \times 10^{4}$ cells per well. The cells were pretreated with $10 \mu \mathrm{M}$ NADPH or $1 \mu \mathrm{M}$ SB203580 (S1863, Beyotime, Nantong, China) for $1 \mathrm{~h}$ and then exposed to $\mathrm{MPP}^{+}$ $(200 \mu \mathrm{M})$ for $12 \mathrm{~h}$. After the treatment, the culture medium was aspirated out and the cells were incubated with Hoechst 33342 $(10 \mu \mathrm{g} / \mathrm{ml}$ in PBS) in the dark for $10 \mathrm{~min}$ at room temperature. Wash the cells twice with PBS and images were captured with a fluorescent microscopy. To count the condensed nuclei, three visual fields were randomly chosen and then the total nuclei and condensed nuclei were determined. The results were expressed as condensed nuclei/total nuclei $\times 100 \%$. The trials were duplicated three times. 

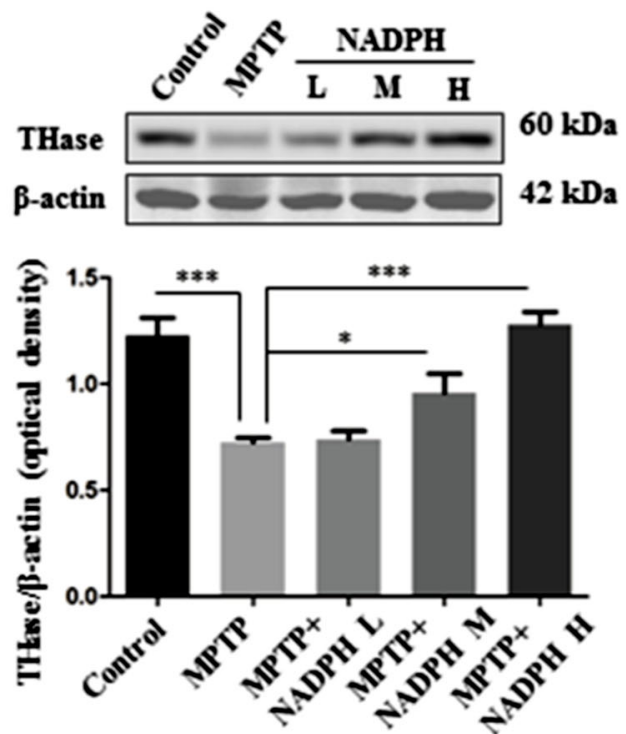

c

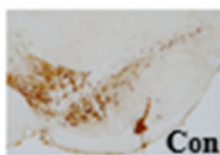

Con
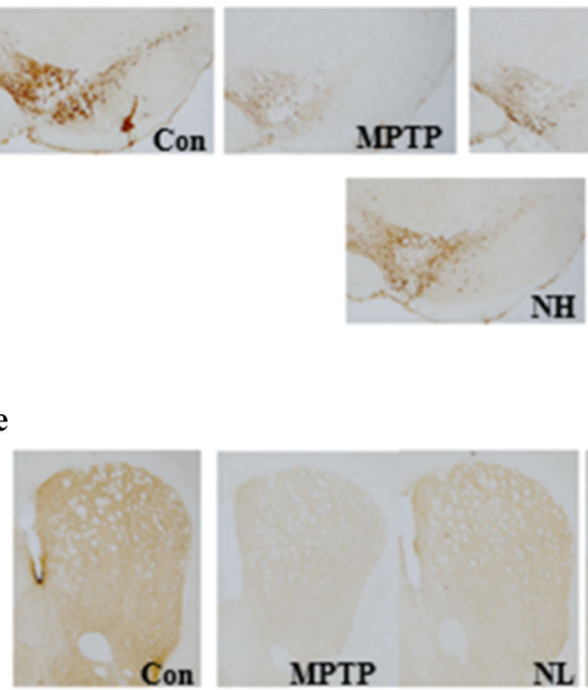

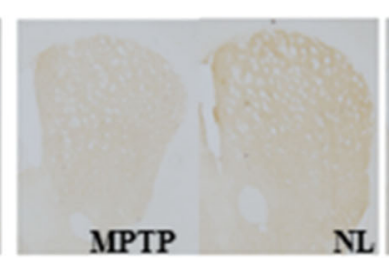

NH
NL

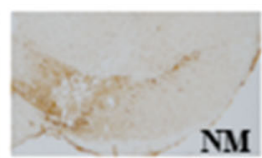

NM

Fig. 1 NAPDH reduced the MPTP-induced damage of DA neurons. a, b THase protein levels in mesencephalic tissues and striatal tissues in normal control, MPTP model, and NADPH-treated groups $(L=2.5 \mathrm{mg} / \mathrm{kg}, M=5 \mathrm{mg} / \mathrm{kg}, H=10 \mathrm{mg} / \mathrm{kg})$. The intensity of each band was normalized to that of $\beta$-actin. All the values represented the mean \pm SEM $\left(n=5\right.$ in each group, ${ }^{*} P<0.05$ vs. MPTP group, ${ }^{* *} P<0.01$ vs. MPTP group, ${ }^{* * *} P<0.001$ vs. MPTP group, one-way ANOVA followed by Student-Newmane-Keuls post hoc test). c, e Representative immunohistochemical images of THase immunoreactivity in SNpc and striatum, respectively. d, $\mathbf{f}$ Quantitative analysis of optical density of THase-positive neurons (d) and fibers (f) in normal control, MPTP model, and NADPH-treated groups $(L=2.5 \mathrm{mg} / \mathrm{kg}, M=5 \mathrm{mg} / \mathrm{kg}$, $H=10 \mathrm{mg} / \mathrm{kg})$. Each value represented the mean \pm SEM $\left(n=3\right.$ in each group, ${ }^{*} P<0.05$ vs. MPTP group, one-way ANOVA followed by Student-Newmane-Keuls post hoc test)

Separation of nuclear and cytoplasmic proteins

MES23.5 cells were seeded in dish with diameter of $10 \mathrm{~cm}$. The cells were pretreated with $10 \mu \mathrm{M}$ NADPH or $1 \mu \mathrm{M}$ SB203580 for $1 \mathrm{~h}$ and followed by incubation with $200 \mu \mathrm{M} \mathrm{MPP}^{+}$. After $10 \mathrm{~h}$ treatment, the cells were harvested and the nuclear and cytoplasmic proteins were separated with the Nuclear and Cytoplasmic Protein Extraction Kit (Beyotime) following the manufacturer's protocols. The proteins were detected with western blot analysis.
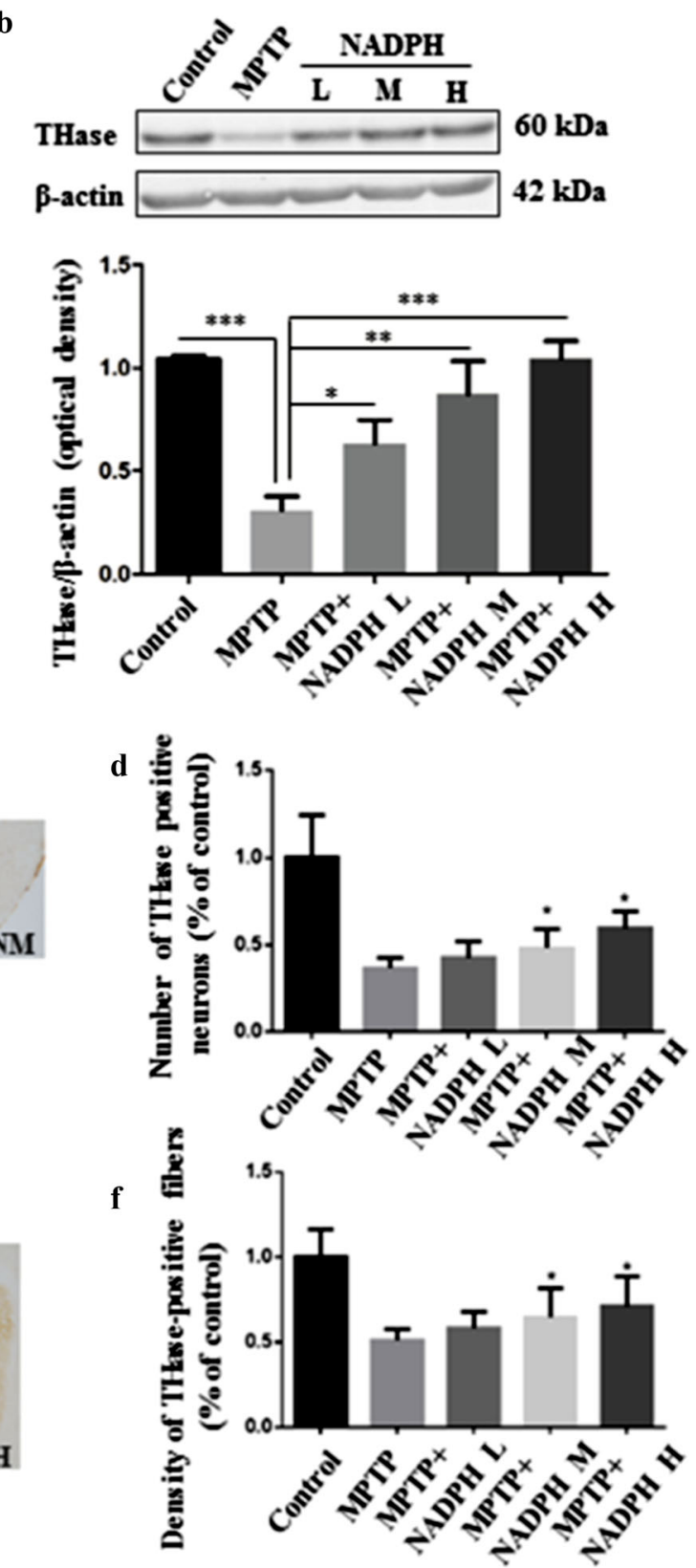

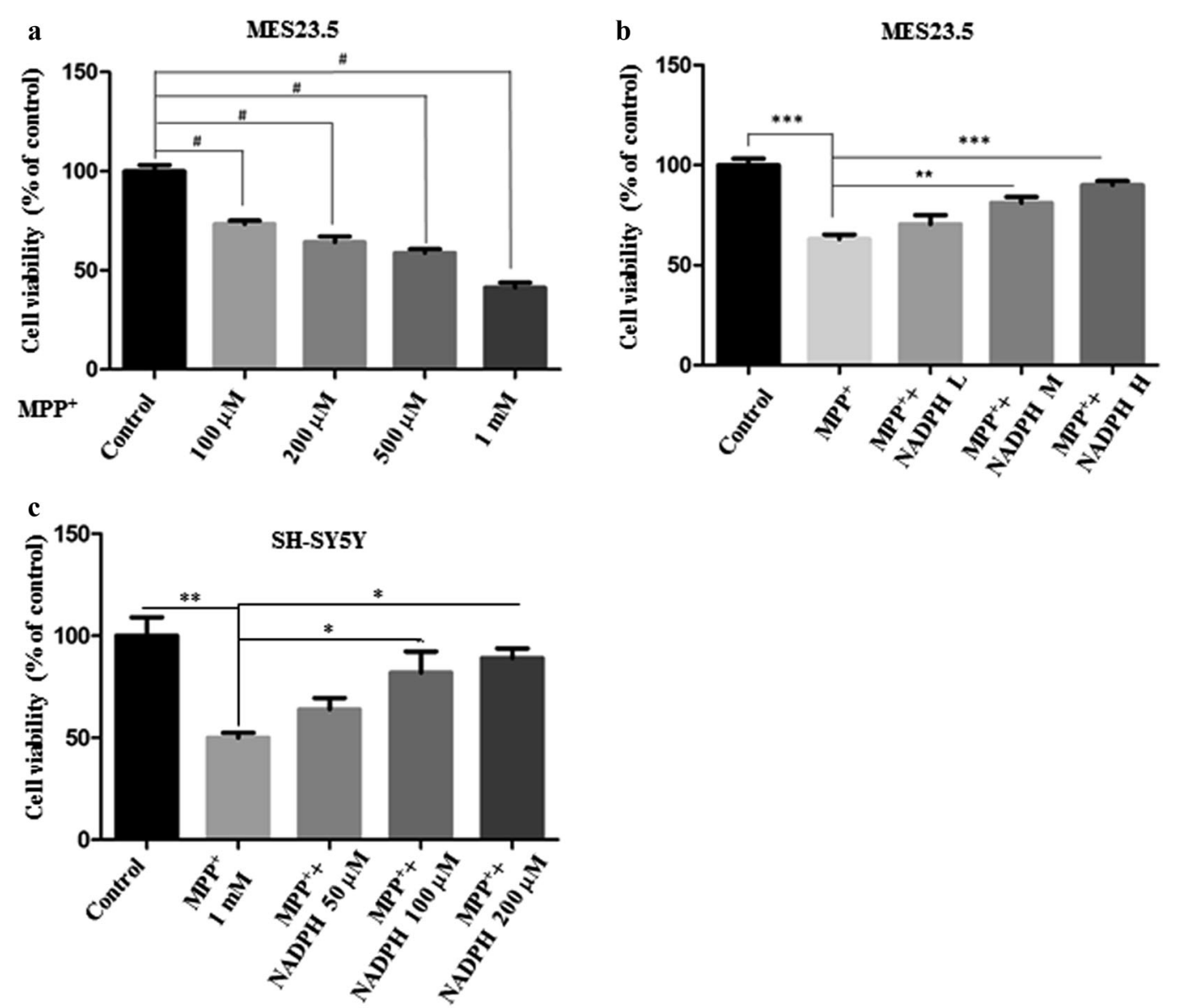

Fig. 2 NADPH protected MES23.5 cells and SH-SY5Y cells from MPP ${ }^{+}$-induced injury. a Neurotoxic effects of MPP ${ }^{+}$on the viability of MES23.5 cells. These data are means $\pm \operatorname{SEM}\left(n=5,{ }^{\#} P<0.001\right.$ significantly different from the control group, one-way ANOVA followed by Student-Newmane-Keuls post hoc test). $\mathbf{b}$ The effects of NADPH $(L=5 \mu \mathrm{M}, M=10 \mu \mathrm{M}, H=20 \mu \mathrm{M})$ on the viability of MES23.5 cells subjected to $200 \mu \mathrm{M} \mathrm{MPP}{ }^{+}$-induced injury. These data are means \pm SEM $\left(n=5,{ }^{* *} P<0.01\right.$ significantly different from the MPP ${ }^{+}$group, ${ }^{* * *} P<0.001$ significantly different from the $\mathrm{MPP}^{+}$group, one-way ANOVA followed by Student-Newmane-Keuls post hoc test). c The effects of NADPH on the viability of SH-SY5Y cells subjected to $1 \mathrm{mM}$ MPP $^{+}$-induced injury. These data are means \pm SEM $(n=5$, ${ }^{*} P<0.05$ significantly different from the $\mathrm{MPP}^{+}$group, ${ }^{* *} P<0.01$ significantly different from the MPP ${ }^{+}$group, one-way ANOVA followed by Student-Newmane-Keuls post hoc test)

measured. Then, the speed of rotation was gradually increased from 4 to $40 \mathrm{rpm}$ within $5 \mathrm{~min}$. The time taken to fall (in seconds, three trials) from the rotarod was recorded.

Beam walk test. A wooden beam, $95 \mathrm{~cm}$ long and $35 \mathrm{~mm}$ wide, was elevated $57 \mathrm{~cm}$ above the floor. The mice were placed on one end of the beam and trained to walk toward the other end. To quantify motor deficits, the time to cross the beam was recorded. The data are presented as the mean of three trials per mice.

Statistical analysis

Data were presented as mean \pm SEM and were evaluated with one-way ANOVA with Student-Newmane-Keuls post hoc test for comparisons of more than two means. Statistical significance was set at $P<0.05$. All statistical analysis was undertaken using Graghpad 5.

\section{RESULTS}

NAPDH reduced the MPTP-induced degeneration of DA neurons The MPTP-induced PD model has been extensively used for recapitulation of several cardinal features of $P D$, such as $D A$ neuronal loss in the SNpc and depletion of dopamine level in the striatum [18]. THase is a key enzyme in dopamine production and marker of DA neurons [19]. To determine if NADPH protected DA neurons from MPTP neurotoxicity, western blot was used to assess the levels of THase protein in SNpc and striatum of mice. As shown in Fig. 1a, b, MPTP administration significantly decreased the levels of THase protein in both SNpc and striatum compared with control group, whereas NADPH treatment significantly reduced the decrease in a dose-dependent manner. Similar protective effects of NADPH on THase were observed with the immunohistochemical staining. The number of THase-positive neurons in $\mathrm{SNpc}$ and intensity of THase-positive fibers in the striatum significantly decreased after MPTP exposure compared with control group, whereas NADPH treatment significantly reduced THase loss in a dose-dependent manner in both SNpc and striatum (Fig. 1c-f).

MES23.5 cells, a dopaminergic cell line that is hybridized from rat mesencephalic neurons with neuroblastoma-glioma N18TG2 cells [20], were chose to produce PD model in vitro. As shown in Fig. 2a, MPP ${ }^{+}$decreased the cell viability of MES23.5 in a concentration-dependent manner. Treatment of MES23.5 cells with $\mathrm{MPP}^{+}$at $200 \mu \mathrm{M}$ for $24 \mathrm{~h}$ caused a decrease of about $60 \%$ of cell viability, thus this treatment condition was applied in 
a

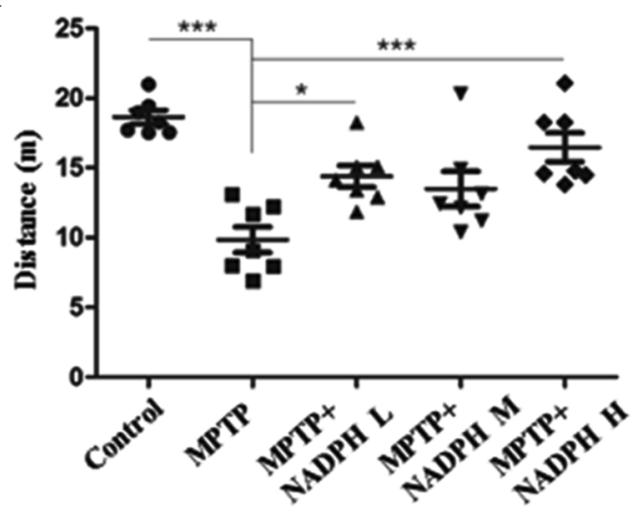

c

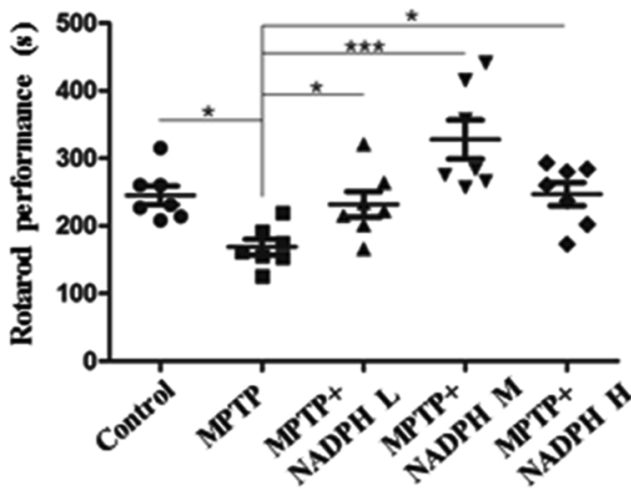

b

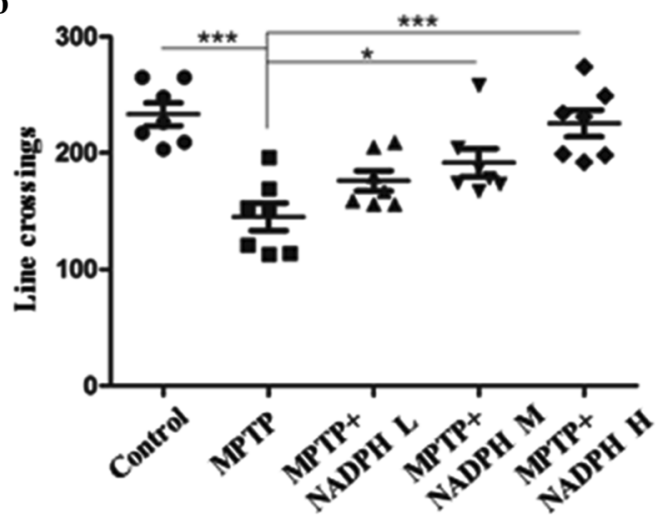

d

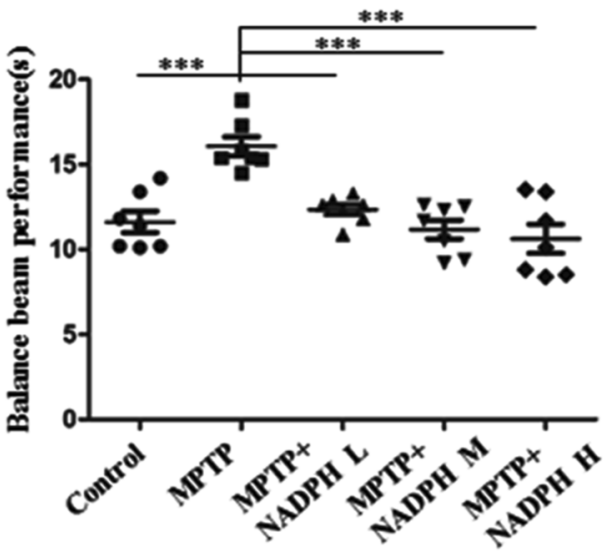

Fig. 3 Effects of NADPH on behavioral impairments induced by MPTP. $\mathbf{a}, \mathbf{b}$ The performance of mice in open field trial. $\mathbf{a}$ The total distance the mice moved in $5 \mathrm{~min}$. b The frequency of line crossing in $5 \mathrm{~min}$. $\mathbf{c}$ The time of the mice fell down from the rotarod. $\mathbf{d}$ The time of the mice went through the balance beam in normal control, MPTP model, and NADPH-treated groups $(L=2.5 \mathrm{mg} / \mathrm{kg}, M=5 \mathrm{mg} / \mathrm{kg}, H=10 \mathrm{mg} / \mathrm{kg})$. Each value represented the mean \pm SEM $\left(n=7\right.$ in each group, ${ }^{*} P<0.05$ vs. MPTP group, ${ }^{* *} P<0.01$ vs. MPTP group, ${ }^{* *} P<0.001$ vs. MPTP group, one-way ANOVA followed by Student-Newmane-Keuls post hoc test)

following experiments. As shown in Fig. 2b, pretreatment of $\mathrm{NADPH}$, at the concentration range $5-20 \mu \mathrm{M}(L=5 \mu \mathrm{M}, M=10$ $\mu \mathrm{M}, H=20 \mu \mathrm{M})$, restored the cell viability in a concentrationdependent manner in the presence of $200 \mu \mathrm{M} \mathrm{MPP}{ }^{+}$. In another study with SH-SY5Y cells, we found that the cell viability was approximate $50 \%$ of the control when the cells were exposed to $1 \mathrm{mM} \mathrm{MPP}^{+}$. And on this condition, NADPH also significantly reduced $\mathrm{MPP}^{+}$toxicity, although required higher concentration of NADPH (Fig. 2c).

NADPH treatment reduced MPTP-induced behavioral impairments Behavioral deficits, particularly in terms of motor activity, are widely used to investigate the relationship between DA neurons degeneration and recovery processes in MPTP-induced model of PD [21]. To explore the effects of NADPH on behavioral impairments induced by MPTP, open field test, rotarod test, and beam walk test were carried out. As shown in Fig. 3a, b, in open field test, the total distance the mice moved in $5 \mathrm{~min}$ and the frequency of line crossing significantly decreased in MPTP group compared with the control group. While NADPH treatment significantly increased both the indexes compared with MPTP mice at all doses. In rotarod test, the time the mice stayed on the rotarod was significantly decreased after MPTP administration, while NADPH treatment significantly prolonged the time (Fig. 3c).

In beam walk test, the time the MPTP mice walked through the beam was significantly increased compared with the control group and NADPH treatment significantly reduced the time in a dose-dependent manner (Fig. 3d).
Obviously, NADPH treatment reduced MPTP-induced behavioral impairments. Combined with the morphology results above, it indicates that NADPH ameliorated MPTP-induced dopaminergic neurodegeneration.

NADPH increased the level of GSH and reduced the production of ROS

There is evidence that the level of GSH decreases in ventral mesencephalon of PD patients [22]. MPTP administration significantly decreased the level of GSH in ventral mesencephalon of mice compared with the control group, while NADPH treatment significantly recovered GSH levels (Fig. $4 a$, b). The production of ROS in ventral mesencephalon of MPTP-treated mice was robustly increased, while NADPH treatment significantly reduced it (Fig. 4c).

DHE staining of MES23.5 indicated that MPP ${ }^{+}$increased ROS production, while the increase was inhibited by the treatment of exogenous NADPH (Fig. 4d). Similarly, addition of $\mathrm{N}$-acetyl-Lcysteine (NAC), an accepted antioxidant which has the effect on scavenging free radicals [23], which is also used in the clinical studies for PD patients [24], decreased MPTP-induced ROS production as well.

NADPH inhibited the MPTP-induced phosphorylation of p38MAPK Several studies revealed that MPTP caused cell-specific activation of phosphorylation cascade of mitogen-activated protein kinase (MAPK) [25]. As shown in Fig. 5c, there was a significant increase in p38MAPK phosphorylation in SNpc of MPTP mice compared with 


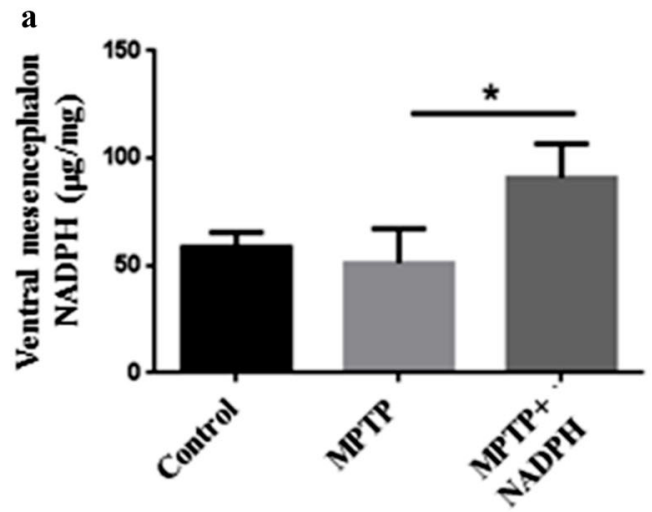

c
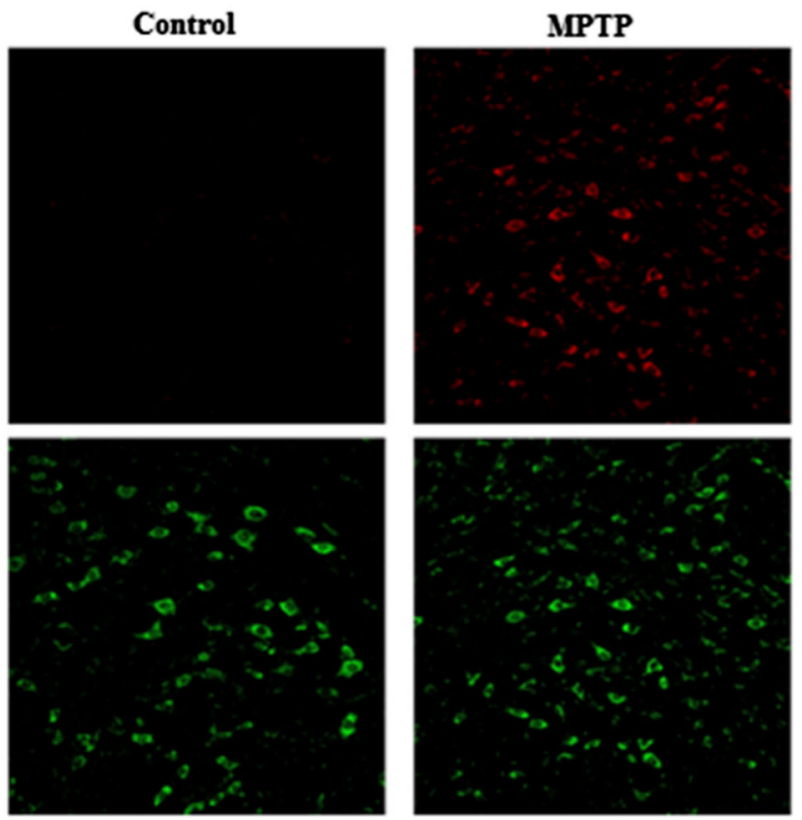

d
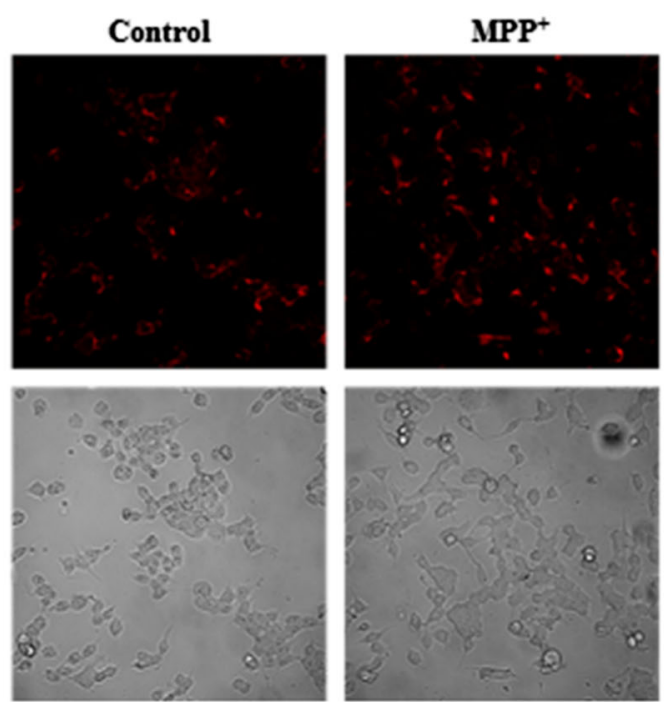

b

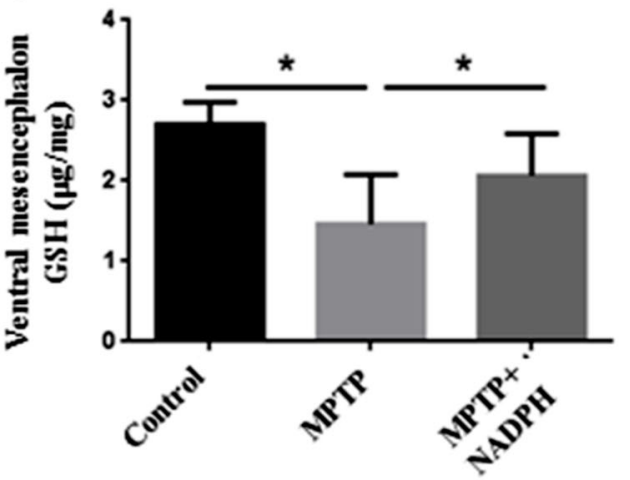

MPTP+NADPH
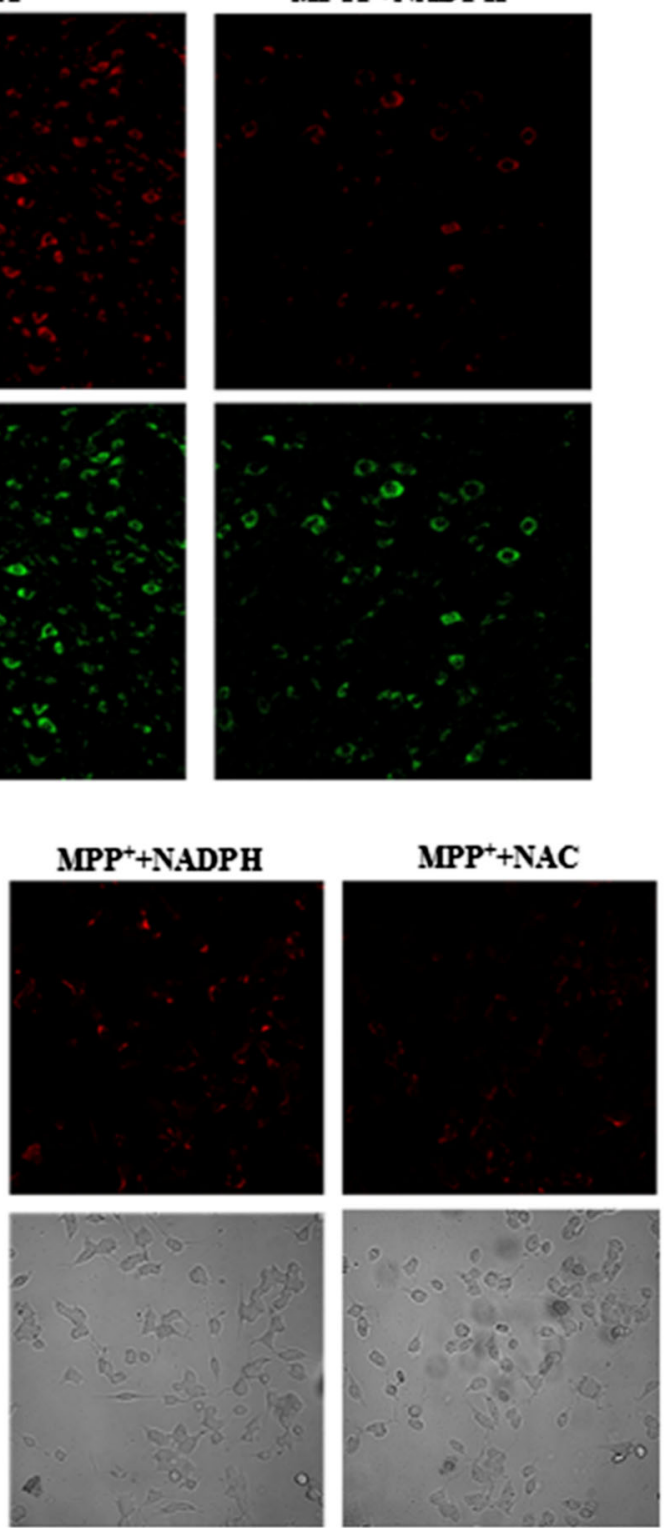

Fig. 4 NADPH increased the levels of GSH and reduced ROS levels in mesencephalon of MPTP-treated mice. $\mathbf{a}$, $\mathbf{b}$ The levels of NADPH and GSH in normal control, MPTP model, and NADPH-treated groups. These data are means \pm SEM $\left(n=6,{ }^{*} P<0.05\right.$ significantly different from the MPTP group, one-way ANOVA followed by Student-Newmane-Keuls post hoc test). c DHE staining was used to evaluate the levels of ROS in the SNpc of mice. Immunofluorescence images were acquired using a confocal microscopy stained for DHE (red) and THase (green) ( $\times 20$ magnification). $\mathbf{d}$ MES23.5 cells were pretreated with $10 \mu \mathrm{M}$ NADPH or $0.5 \mathrm{mM}$ NAC for $1 \mathrm{~h}$ and then exposed to $200 \mu \mathrm{M}$ MPP ${ }^{+}$for $12 \mathrm{~h}$. DHE staining was used to evaluate the intracellular ROS production in MES23.5 cells. The fluorescence was detected with a confocal microscopy ( $\times 20$ magnification) 


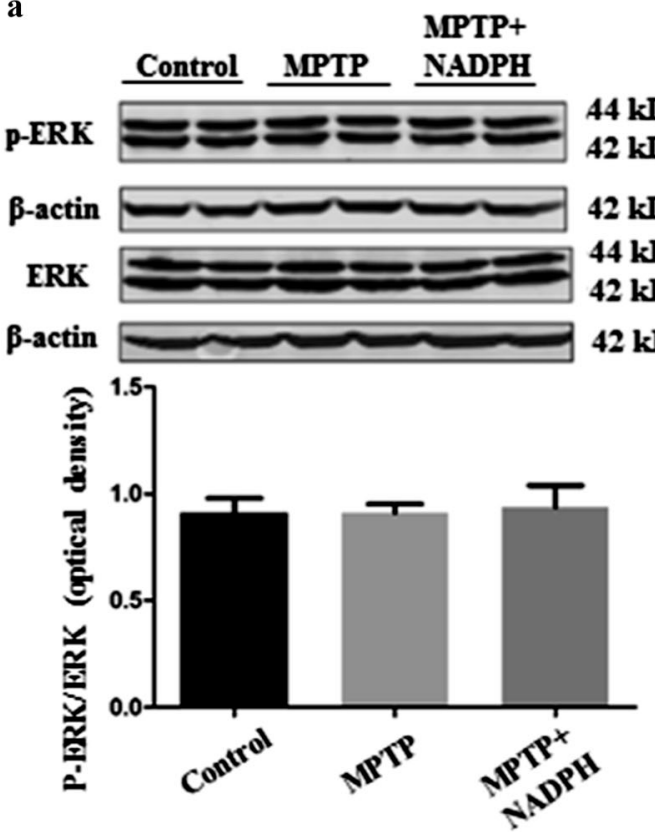

c

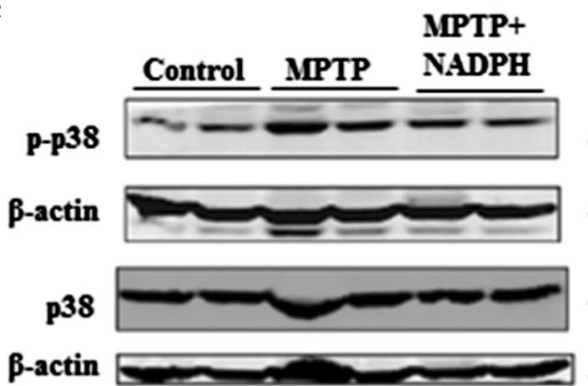

$43 \mathrm{kDa}$

$42 \mathrm{kDa}$

$43 \mathrm{kDa}$

$42 \mathrm{kDa}$

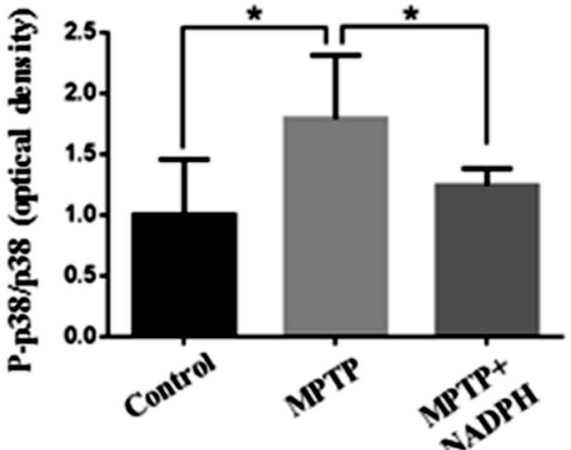

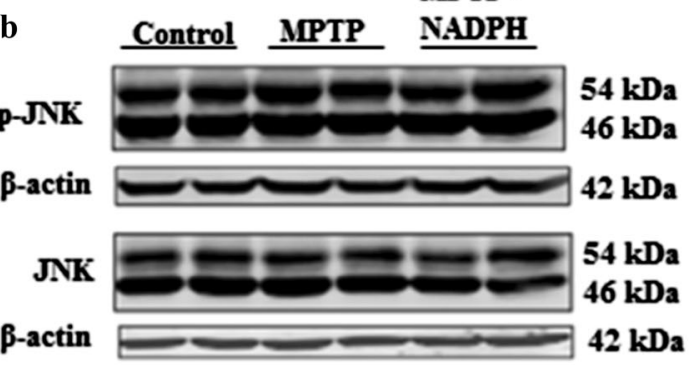

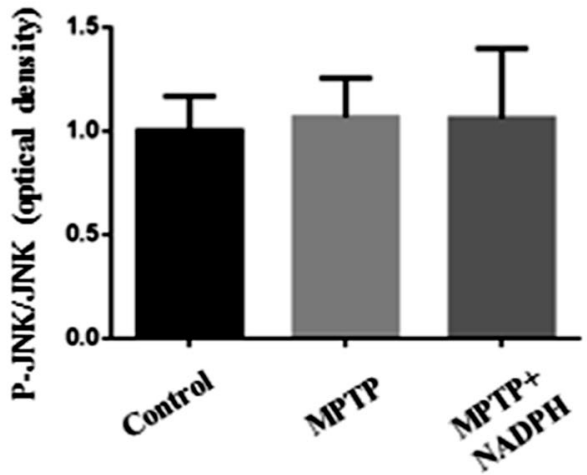

d
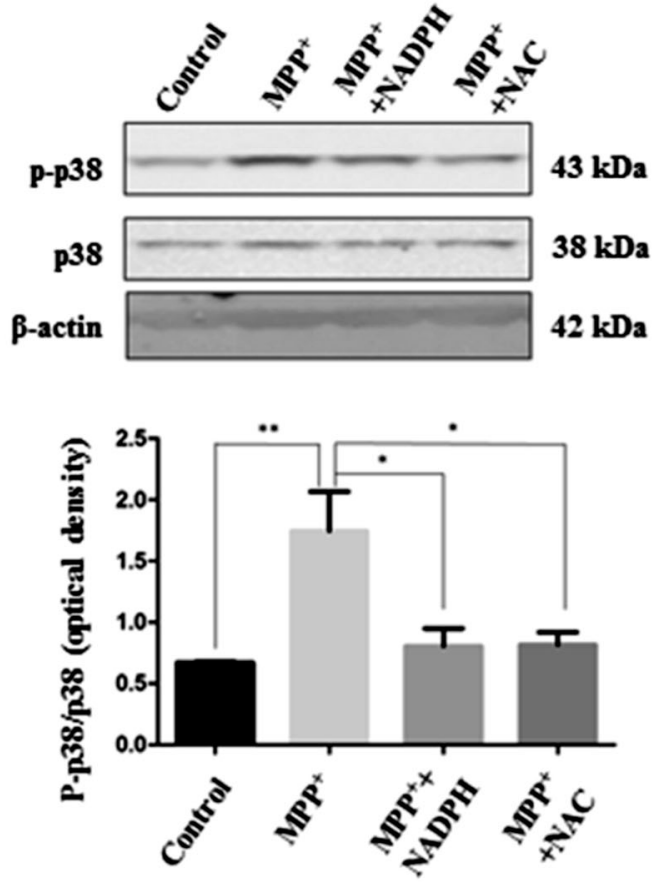

Fig. 5 NADPH inhibited the MPTP-induced phosphorylation of p38MAPK. a-c The representative western blotting and quantitative analysis of levels of ERK, JNK, and P38MAPKs and their phosphorylated form in the SNpc of mice. These data are means \pm SEM ( $n=5$ in $\mathbf{a}$ and $\mathbf{c}, n=3$ in $\mathbf{b}$, ${ }^{*} P<0.05$ significantly different from the MPTP group, one-way ANOVA followed by Student-Newmane-Keuls post hoc test). $\mathbf{d}$ The expression of p38MAPK and its phosphorylated form was measured with western blotting. The MES23.5 cells were pretreated with $10 \mu \mathrm{M}$ NADPH or $0.5 \mathrm{mM} \mathrm{NAC}$ for $1 \mathrm{~h}$ and followed by exposure to $200 \mu \mathrm{M} \mathrm{MPP}^{+}$for $30 \mathrm{~min}$. Then, the cells were harvested for western blot analysis. These data are means \pm SEM $\left(n=5,{ }^{*} P<0.05\right.$ significantly different from the MPP ${ }^{+}$group, ${ }^{* *} P<0.01$ significantly different from the MPP ${ }^{+}$group, one-way ANOVA followed by Student-Newmane-Keuls post hoc test)

the control group, while the level of $\mathrm{p}$-p38 protein was significantly decreased in NADPH-treated mice compared with MPTP mice. However, there was almost no difference in phosphorylated ERK or JNK in ventral midbrain of each group (Fig. 5a, b).
Moreover, in our earlier experiments, we examined the level of p-p38 protein in MES23.5 cells at different time points after treatment with $200 \mu \mathrm{M} \mathrm{MPP}{ }^{+}$, and found that the first peak of p-p38 appeared 30 min post the treatment. When examined at this time point, NADPH significantly inhibited $\mathrm{MPP}^{+}$-induced 


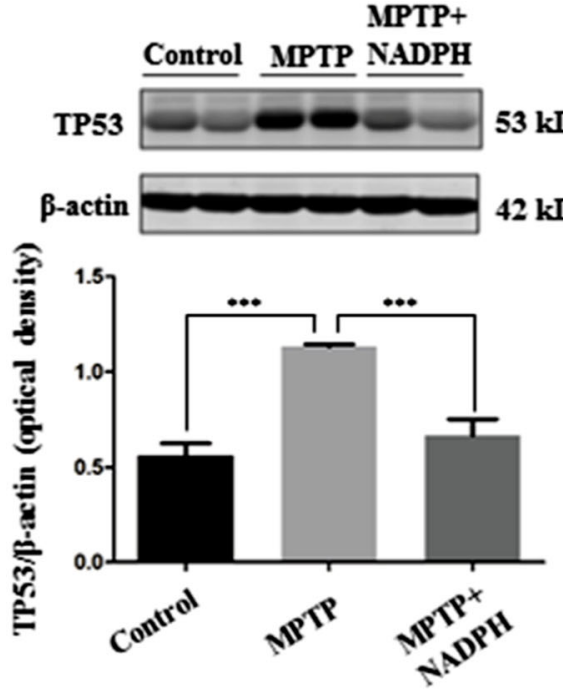

b
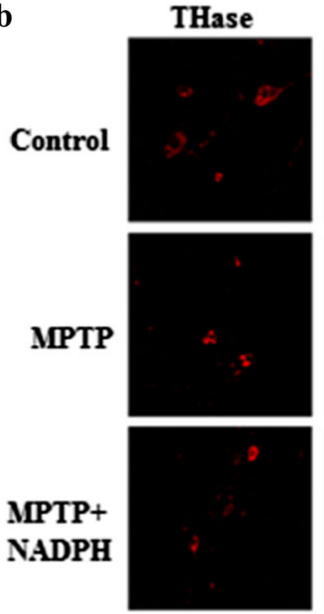
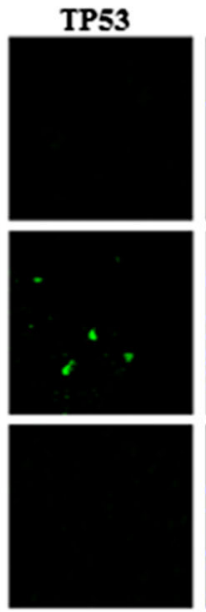
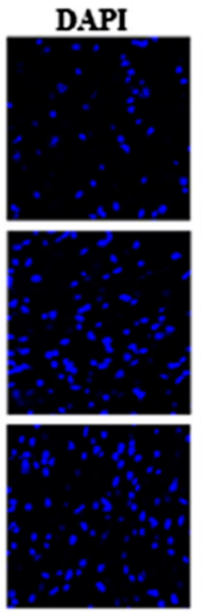
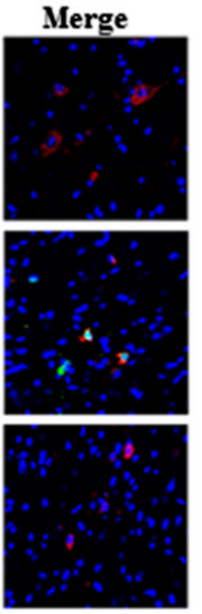

c

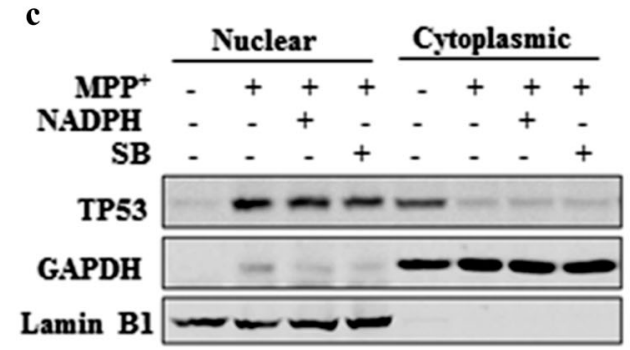

$53 \mathrm{kDa}$ $37 \mathrm{kDa}$ $68 \mathrm{kDa}$
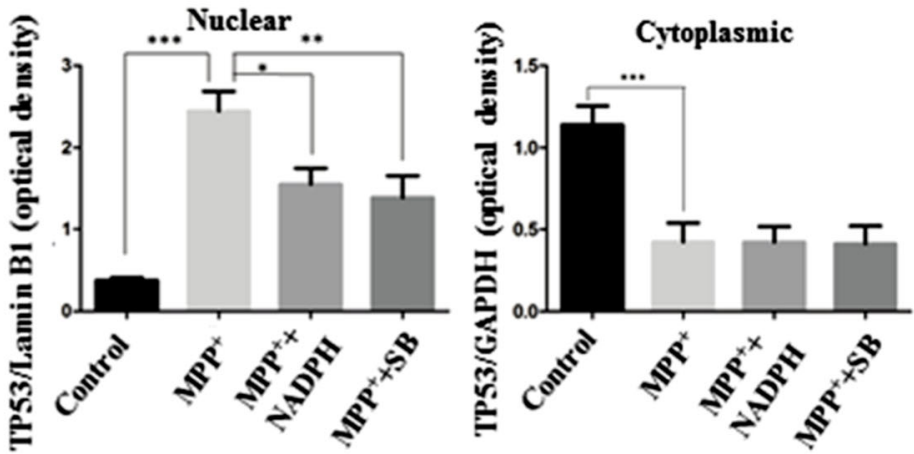

Fig. 6 NADPH inhibited MPTP-induced TP53 nuclear translocation. a The representative western blotting and quantitative analysis of TP53 in the SNpc of mice. These data are means \pm SEM $\left(n=5,{ }^{* * *} P<0.001\right.$ significantly different from the MPTP group, one-way ANOVA followed by Student-Newmane-Keuls post hoc test). $\mathbf{b}$ The effects of NADPH on the translocation of TP53 in the SNpc of MPTP mice detected with a confocal microscopy ( $\times 20$ magnification). c MES23.5 cells were pretreated with $10 \mu \mathrm{M}$ NADPH or $1 \mu \mathrm{M}$ SB203580 for $1 \mathrm{~h}$ and then exposed to $200 \mu \mathrm{M} \mathrm{MPP}^{+}$for $12 \mathrm{~h}$. After separation of the nuclear and cytoplasmic proteins, western blotting was used to detect the levels of TP53. These data are means \pm SEM $\left(n=5,{ }^{*} P<0.05\right.$ significantly different from the MPP ${ }^{+}$group, ${ }^{*} P<0.01$ significantly different from the MPP ${ }^{+}$ group, ${ }^{* *} P<0.001$ significantly different from the MPP ${ }^{+}$group, one-way ANOVA followed by Student-Newmane-Keuls post hoc test)

increase in level of p-p38 protein. Similarly, another antioxidant NAC also exerted inhibitory effects on $\mathrm{MPP}^{+}$-induced upregulation of $\mathrm{p}$-p38, suggesting that ROS played a role in phosphorylation of p38MAPK and NADPH may inhibit the activation of p38MAPK through reducing $\mathrm{ROS}$ (Fig. $5 \mathrm{~d}$ ).

NADPH inhibited MPTP-induced TP53 nuclear translocation and apoptosis

Considering apoptosis plays an important role in MPTP-induced damage of DA neurons [26], the effect of NADPH on apoptosisrelated proteins was investigated. TP53 is a cellular stress sensor, which triggers apoptosis under various stress [27]. Previous reports found that selective p38MAPK activation resulted in phosphorylation and nuclear translocation of TP53 in MPTPtreated mice [28]. As shown in Fig. 6a, in the MPTP-treated group, the level of TP53 was increased compared with control group. However, the treatment of NADPH significantly attenuated the MPTP-induced increase in TP53 levels. Meanwhile, MPTP induced TP53 nuclear translocation in DA neurons of SNpc, while NADPH treatment prevented MPTP-induced TP53 nuclear translocation (Fig. 6b).

Previous studies reported that MPTP-induced phosphorylation and nuclear translocation of TP53 following p38MAPK activation in the ventral midbrain of MPTP-treated mice [28]. In our earlier experiments in MES23.5 cells, we found that the level of nuclear TP53 protein increased significantly at $12 \mathrm{~h}$ of time point. After separation of the nuclear and cytoplasmic proteins at this point, as shown in Fig. 6c, western blot assay showed that both NADPH and SB203580 inhibited $\mathrm{MPP}^{+}$-induced TP53 nuclear translocation, demonstrating that NADPH inhibited $\mathrm{MPP}^{+}$-induced nuclear translocation of TP53 though p38MAPK pathway.

The level of Bax, a downstream regulator of TP53 in triggering cell apoptosis, was detected with western blotting. MPTP induced a remarkable elevation in the level of Bax protein. The treatment with NADPH blunted the increase in Bax (Fig. 7a). To test if the increase in Bax was dependent on p38MAPK, the effect of SB203580 was determined. The level of Bax protein in MES23.5 cells was detected at $12 \mathrm{~h}$ of time point, when we found a significant increase in Bax protein level in our earlier experiments. The results showed that $\mathrm{MPP}^{+}$-induced increase in the level of Bax was remarkably downregulated by both NADPH and SB203580, indicating that NADPH decreased the expression of Bax through p38MAPK (Fig. 7b).

Bax provokes apoptosis via activation of intrinsic caspasedependent pathways in mitochondria, and the active caspase 3 induces subsequent cleavage of PARP to execute the apoptotic 


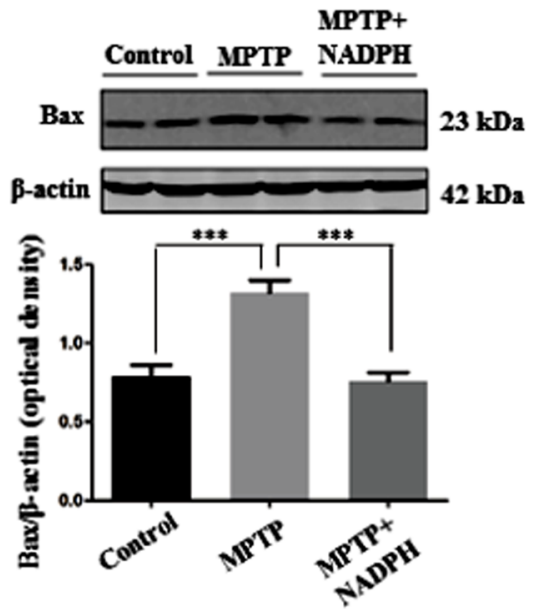

c
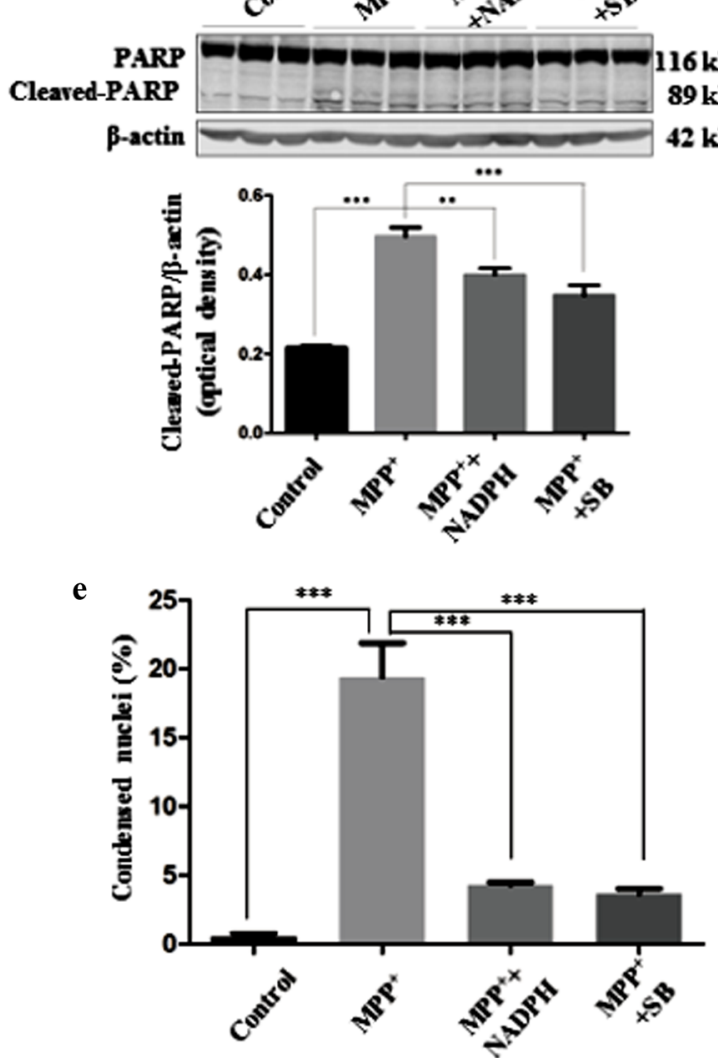

b
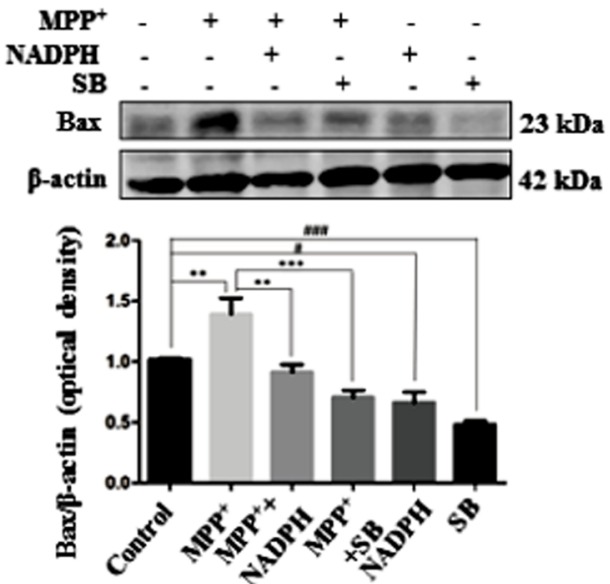

d

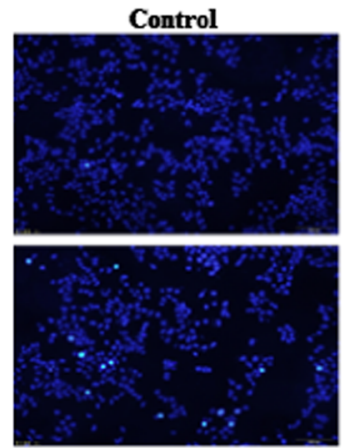

$\mathrm{MPP}^{+}+\mathbf{N A D P H}$
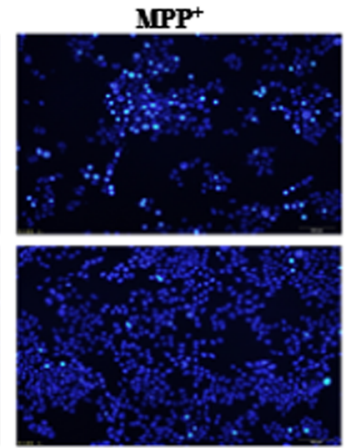

$\mathrm{MPP}^{+}+\mathrm{SB}$

$116 \mathrm{kDa}$

$42 \mathrm{kDa}$

Fig. 7 NADPH inhibited MPTP-induced apoptosis. MES23.5 cells were exposed to $200 \mu \mathrm{M} \mathrm{MPP}{ }^{+}$for $12 \mathrm{~h}$ after pretreatment with $10 \mu \mathrm{M}$ NADPH or $1 \mu \mathrm{M} \mathrm{SB203580}$ for $1 \mathrm{~h}$. a The representative western blotting and quantitative analysis of Bax in the SNpc of mice. These data are means \pm SEM $\left(n=5,{ }^{* * *} P<0.001\right.$ significantly different from the MPTP group, one-way ANOVA followed by Student-Newmane-Keuls post hoc test). b Western blotting and quantitative analysis of Bax in MPP ${ }^{+}$-treated MES23.5 cells. These data are means \pm SEM $(n=5$, **P $<0.01$ significantly different from the MPP ${ }^{+}$group, ${ }^{* * *} P<0.001$ significantly different from the $\mathrm{MPP}^{+}$group, ${ }^{*} P<0.05$ significantly from the control group,

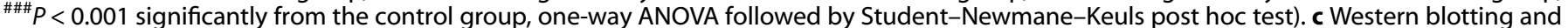
quantitative analysis of cleaved-PRAP in MPP ${ }^{+}$-treated MES23.5 cells. These data are means \pm SEM $\left(n=6,{ }^{* *} P<0.01\right.$ significantly different from the $\mathrm{MPP}^{+}$group, ${ }^{* * *} P<0.001$ significantly different from the MPP ${ }^{+}$group, one-way ANOVA followed by Student-Newmane-Keuls post hoc test). d The representative photograph of Hoechst 33342 staining of MES23.5 cells after MPP ${ }^{+}$treatment ( $\times 20$ magnification). e Quantitative analysis of percentage of nuclear condensation stained with Hoechst 33342 in MES23.5 cells after exposure to MPP ${ }^{+}$. These data are means \pm SEM $\left(n=3,{ }^{* * *} P<0.001\right.$ significantly different from the MPP ${ }^{+}$group, one-way ANOVA followed by Student-Newmane-Keuls post hoc test)

process, leading to phosphatidylserine translocation [29]. Our results showed that when MES23.5 cells were exposed to MPP', the level of cleaved PARP was significantly elevated and both
NADPH and SB203580 retarded the increase (Fig. 7c). To confirm if $\mathrm{NADPH}$ protects DA neurons from $\mathrm{MPP}^{+}$-induced apoptosis, we stained MES23.5 cells with Hoechst 33342 and examined nuclear 
condensation as an index of apoptosis. As shown in Fig. 7d, e, exposure of MES23.5 cells to MPP ${ }^{+}$for $12 \mathrm{~h}$ caused robust nuclear condensation, pretreatment with SB203580, or NADPH significantly attenuated $\mathrm{MPP}^{+}$-induced condensation of nuclei, indicating that NADPH exerted its anti-apoptotic effects by inhibiting the activation of p38MAPK.

\section{DISCUSSION}

In our previous studies, we reported that NADPH has potent neuroprotective effects against ischemic neuronal injury $[30,31]$. The present study found that NADPH inhibited MPTP/MPP ${ }^{+}$ induced damage of dopaminergic neurons. Pretreatment with NADPH significantly reduced the loss of dopaminergic neurons in MPTP-induced mice PD model. The recovery of THase immunoactivity in substantial nigra and striatum appeared not as effective as that of the protein levels detected with western blot analysis. These could be caused by different detection methods. In our previous study, we reported that NADPH reduced $\mathrm{H}_{2} \mathrm{O}_{2}$ toxicity in cultured primary neurons through reducing ROS [32]. In this study, we also observed potent neuroprotective effects of NADPH in cultured dopaminergic MES23.5 cells and SH-SY5Y cells. NADPH ameliorated MPTP/MPP ${ }^{+}$cytotoxicity through reducing ROS, p38MAPK phosphorylation, and TP53 activation. The present study suggests that NADPH may be a candidate of therapeutic drug for $P D$.

$\mathrm{NADPH}$, the pivotal coenzyme involved in GSH antioxidant systems [33], can convert oxidized glutathione (GSSG) into GSH to promote GSH regeneration [34]. GSH, the main source of mercapto in a wide majority of living cells, plays a vital role in maintaining redox state of proper protein thiol [35]. In our present study, NADPH reduced the ROS levels in DA neurons of MPTPtreated mice and MES23.5 cells, which were exposed to MPP ${ }^{+}$.

MAPK, a family of serine/threonine kinase, including ERK1/2, JNK, and p38MAPK, represents important signal transduction machinery and regulates cell signaling in response to various stressors [36]. Previous studies have demonstrated that a variety of physical and chemical stresses, such as hypoxia/ischemia and oxidative stress, could activate the MAPK pathway [37]. It has been reported that accumulated ROS can activate ERKs, JNKs, or p38MAPKs [38]. Although the exact mechanism by which the ROS activate these kinases is still unclear, a plausible mechanism may result from oxidative modifications and resultant activations of the signaling effector proteins and inactivation and degradation of MAPK phosphatases [39]. Nevertheless, a growing body of evidence from experiments in vivo and in vitro suggests that neurotoxins induce selective phosphorylation of p38MAPK within the DA neurons $[28,40]$. Early animal experiments have proved that inhibitors of p38MAPK increase the survival of DA neurons [41]. Other studies have also shown that p38MAPK inhibitors protect cells against the neurotoxicity that induce PD, such as rotenone, 6-OHDA, and MPTP [40-42]. Our present study demonstrated that MPTP significantly increased the phosphorylation of p38MAPK in DA neurons. However, the increase was attenuated by the treatment of NADPH both in vivo and in vitro. Meanwhile, NAC, an effective antioxidant that helps to increase GSH synthesis and directly scavenges ROS [43], had the similar effects to NADPH in vitro. Based on our previous study and the present data, we think NADPH inhibited p38 phosphorylation through reducing ROS. But exact mechanisms of action of NADPH require more detailed investigation.

p38MAPK pathway has been shown to be involved in apoptosis [44]. In previous study, 6-OHDA induces apoptosis through p38MAPK-dependent, TP53-independent activation of Bax in the rat model of PD [45]. P38MAPK promotes cell apoptosis by activation of TP53. TP53 induces the activation of mitochondrial apoptotic pathways, which including transcription of Bax, and activation of caspases $[40,42]$. Previous studies reported that

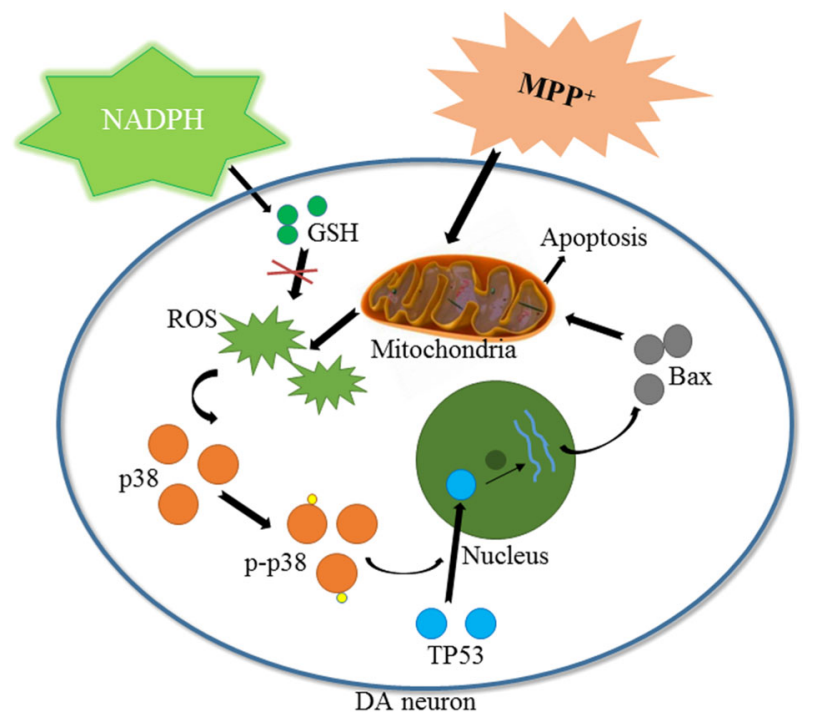

Fig. 8 A schematic diagram showing how NADPH attenuated MPTPinduced cytotoxicity in DA neurons. MPTP injured the mitochondria while NADPH rescued DA neurons from the neurotoxin through maintaining GSH level and suppressing ROS. NADPH inhibited the nuclear translocation of TP53, upregulation of Bax, and apoptosis of DA neurons through abrogation of p38MAPK phosphorylation activated by excessive ROS

MPTP-induced phosphorylation and the nuclear translocation of TP53 following p38MAPK activation in the ventral midbrain of MPTP-treated mice [28]. Consistently with these results, we demonstrated that p38MAPK is activated by MPTP and its activation caused upregulation of Bax in SNpc of MPTP-treated mice and $\mathrm{MPP}^{+}$-treated MES23.5 cells, which might result in apoptosis. Our data showed that both NADPH and SB203580 significantly inhibited the nuclear translocation of TP53, reduced the levels of Bax, and cleaved PARP in MES23.5 cells. Furthermore, both NADPH and SB203580 significantly reduced $\mathrm{MPP}^{+}$-induced nuclear condensation, an index of apoptosis. These results suggest that NADPH suppresses apoptosis through inhibiting the activation of p38MAPK.

However, TP53 can upregulate a variety of apoptotic factors in addition to Bax [46]. It was reported that MPTP/MPP ${ }^{+}$increased the expression of pro-apoptotic protein PUMA in PC12 cells [47], and Fas in the mice brain tissues [48]. There is evidence that MPTP induces the increase of Smac [49]. Moreover, upregulated BAX may link mitochondria with apoptosis via caspase 3-independent pathway [50].

The cause of PD and the mechanism of neuronal death in PD are not fully understood. Many potential mechanisms have been implicated in pathogenesis of PD [51-55]. In MPTP-induced PD models, multiple mechanisms are involved in neuronal death, including oxidative stress [56], the mitochondrial apoptotic cascade [57], excitotoxicity [58], inflammation [59], abnormal protein interactions in the ubiquitin-proteasome system (UPS) [60], and so on [61]. Thus, it should be pointed out that neuroprotection exerted by NADPH may involve other signaling pathways in addition to p53-mediated cell death pathway. Further study is warranted to detail neuroprotective mechanisms of NADPH.

It should also be noted that the MPTP-induced PD model reflects an acute cell death progress, which likely is very different from the slow degeneration process of dopaminergic and other neurons in PD patients that happen over years. Currently, no PD models can fully recapitulate the phenotypes and pathology observed in PD patients, such as progressive deterioration of behaviors and pathology with age, or fluctuations in motor 
functions. Altghough preclinical studies of antioxidant therapy for PD have shown promising results [62-64], the clinical trials have so far generated limited clinical efficacy, and clinical effective antioxidants are yet to be found [65]. As an efficient antioxidant, the clinical effect of NADPH on PD remains to be tested.

In summary, we explored the neuroprotective effects of NADPH in $\mathrm{MPP}^{+}$-treated cellular and MPTP-induced mice models of PD, in vivo and vitro MPTP models. Our results demonstrated that NADPH rescued DA neurons, maintained GSH level, and suppressed ROS. NADPH inhibited the nuclear translocation of TP53, upregulation of Bax, and apoptosis of DA neurons through preventing excessive ROS-mediated p38MAPK phosphorylation (Fig. 8).

\section{ACKNOWLEDGEMENTS}

This study was supported by funds from the National Key Basic Science Research Project (973 Project, 2011CB510003); the Natural Science Foundation of China (No.31300893).

\section{AUTHOR CONTRIBUTIONS}

Z.Q., R.S., J.W., and Z.Z. designed the experiments. J.Z, F.W., and Y.Z. performed the experiments. J.Z., Z.Z., and F.W. analyzed the data and designed the artwork. J.Z. wrote the main text. Z.Z., F.W., and Z.Q. revised the manuscript.

\section{ADDITIONAL INFORMATION}

Competing interests: The authors declare no competing financial interests.

\section{REFERENCES}

1. Lopez IC, Ruiz PJ, Del Pozo SV, Bernardos VS. Motor complications in Parkinson's disease: ten year follow-up study. Mov Disord. 2010;25:2735-9.

2. Wu K, Politis M, Piccini P. Parkinson disease and impulse control disorders: a review of clinical features, pathophysiology and management. Postgrad Med J. 2009;85:590-6.

3. Dehay B, Martinez-Vicente M, Ramirez A, Perier C, Klein C, Vila M, et al. Lysosomal dysfunction in Parkinson disease ATP13A2 gets into the groove. Autophagy. 2012;8:1389-91.

4. Park J, Lee G, Chung J. The PINK1-Parkin pathway is involved in the regulation of mitochondrial remodeling process. Biochem Biophys Res Commun. 2009;378:518-23.

5. Perier C, Bove J, Vila M. Mitochondria and programmed cell death in Parkinson's disease: apoptosis and beyond. Antioxid Redox Signal. 2012;16:883-95.

6. Zeevalk GD, Razmpour R, Bernard LP. Glutathione Glutathione and Parkinson's disease: is this the elephant in the room? Biomed Pharmacother. 2008;62:236-49.

7. Islam MT. Oxidative stress and mitochondrial dysfunction-linked neurodegenerative disorders. Neurol Res. 2017;39:73-82.

8. Fitzmaurice PS, Ang L, Guttman M, Rajput AH, Furukawa $Y$, Kish SJ. Nigral glutathione deficiency is not specific for idiopathic Parkinson's disease. Mov Disord. 2003;18:969-76.

9. Sun Y, Sukumaran P, Selvaraj S, Cilz NI, Schaar A, Lei S, et al. TRPM2 promotes neurotoxin MPP+/MPTP-induced cell death. Mol Neurobiol. https://doi.org/ 10.1007/s12035-016-0338-9 (2016).

10. Bensaad K, Tsuruta A, Selak MA, Vidal MN, Nakano K, Bartrons R, et al. TIGAR, a p53-inducible regulator ofglycolysis and apoptosis. Cell. 2006;126:107-20.

11. Yang HC, Wu YH, Liu HY, Stern A, Chiu DT. What has passed is prolog: new cellular and physiological roles of G6PD. Free Radic Res. 2016;50:1047-64.

12. Ussher JR, Jaswal JS, Lopaschuk GD. Pyridine nucleotide regulation of cardiac intermediary metabolism. Circ Res. 2012;111:628-41.

13. Marino D, Gonzalez EM, Frendo P, Puppo A, Arrese-Igor C. NADPH recycling systems in oxidative stressed pea nodules: a key role for the NADP +-dependent isocitrate dehydrogenase. Planta. 2007;225:413-21.

14. Ratledge $C$. The role of malic enzyme as the provider of NADPH in oleaginous microorganisms: a reappraisal and unsolved problems. Biotechnol Lett. 2014;36:1557-68.

15. Powers R, Lei S, Anandhan A, Marshall DD, Worley B, Cerny RL, et al. Metabolic investigations of the molecular mechanisms associated with Parkinson's disease. Metabolites. 2017;7:22
16. Dunn L, Fairfield V, Daham S, Bolaos JP, Heales SJ. Pentose-phosphate pathway disruption in the pathogenesis ofParkinson's disease. Transl Neurosci. 2014;5:179-84.

17. Li M, Sun M, Cao L, Gu JH, Ge J, Chen J, et al. A TIGAR-regulated metabolic pathway is critical for protection ofbrain ischemia. J Neurosci. 2014;34:7458-71.

18. Jackson-Lewis V, Przedborski S. Protocol for the MPTP mouse model of Parkinson's disease. Nat Protoc. 2007;2:141-51.

19. Cederfjall E, Broom L, Kirik D. Controlled striatal DOPA production from a gene delivery system in a rodent model of Parkinson's disease. Mol Ther. 2015;23:896-906.

20. Crawford GD Jr., Le WD, Smith RG, Xie WJ, Stefani E, Appel SH. A novel N18TG2 x mesencephalon cell hybrid expresses properties that suggest a dopaminergic cell line of substantia nigra origin. J Neurosci. 1992;12:3392-8.

21. Campolo M, Casili G, Biundo F, Crupi R, Cordaro M, Cuzzocrea S, et al. The neuroprotective effect ofdimethyl fumarate in an MPTP-mouse model of Parkinson's disease: involvement of reactive oxygen species/ 11 nuclear factorkappaB/nuclear transcription factor related to NF-E2. Antioxid Redox Signal. 2017;27:453-71.

22. Jha N, Jurma O, Lalli G, Liu Y, Pettus EH, Greenamyre JT, et al. Glutathione depletion in PC12 results in selective inhibition of mitochondrial complex I activity. Implications for Parkinson's disease. J Biol Chem. 2000;275:26096-101.

23. Aruoma OI, Halliwell B, Hoey BM, Butler J. The antioxidant action of N-acetylcysteine: its reaction with hydrogen peroxide, hydroxyl radical, superoxide, and hypochlorous acid. Free Radic Biol Med. 1989;6:593-7.

24. Monti DA, Zabrecky G, Kremens D, Liang TW, Wintering NA, Cai JL, et al. N-acetyl cysteine may support dopamine neurons in Parkinson's disease: preliminary clinical and cell line data. PLoS ONE. 2016;11:e0157602.

25. Kim EK, Choi EJ. Compromised MAPK signaling in human diseases: an update. Arch Toxicol. 2015;89:867-82.

26. Smeyne M, Smeyne RJ. Glutathione metabolism and Parkinson's disease. Free Radic Biol Med. 2013;62:13-25.

27. Marchenko ND, Moll UM. Mitochondrial death functions of p53. Mol Cell Oncol. 2014;1:e955995.

28. Karunakaran S, Saeed U, Mishra M, Valli RK, Joshi SD, Meka DP, et al. Selective activation ofp38 mitogen-activated protein kinase in dopaminergicneurons ofsubstantia nigra leads tonuclear translocation ofp53 in 1-methyl-4-phenyl1,2,3,6-tetrahydropyridine-treated mice. J Neurosci. 2008;28:12500-9.

29. Zhang C, Wang C, Tang S, Sun Y, Zhao D, Zhang S, et al. TNFR1/TNF-alpha and mitochondria interrelated signaling pathway mediates quinocetone-induced apoptosis in HepG2 cells. Food Chem Toxicol. 2013;62:825-38.

30. Li M, Zhou ZP, Sun M, Cao L, Chen J, Qin YY, et al. Reduced nicotinamide adenine dinucleotide phosphate, a pentose phosphate pathway product, might be a novel drug candidate for ischemic stroke. Stroke. 2016;47:187-95.

31. Qin YY, Li M, Feng X, Wang J, Cao L, Shen XK, et al. Combined NADPH and the NOX inhibitor apocynin provides greater anti-inflammatory and neuroprotective effects in a mouse model of stroke. Free Radic Biol Med. 2017;104:333-45.

32. Sun M, Li M, Huang Q, Han F, Gu JH, Xie J, et al. Ischemia/reperfusion-induced upregulation of TIGAR in brain is mediated by SP1 and modulated by ROS and hormones involved in glucose metabolism. Neurochem Int. 2015;80:99-109.

33. Zhou JH, Zhang TT, Song DD, Xia YF, Qin ZH, Sheng R. TIGAR contributes to ischemic tolerance induced by cerebral preconditioning through scavenging of reactive oxygen species and inhibition of apoptosis. Sci Rep. 2016;6:27096.

34. Suzuki M, O'Dea JD, Suzuki T, Agar NS. 2-Deoxyglucose as a substrate for glutathione regeneration in human and ruminant red blood cells. Comp Biochem Physiol B. 1983;75:195-7.

35. Sun HJ, Wang Y, Hao T, Wang CY, Wang QY, Jiang XX. Efficient GSH delivery using PAMAM-GSH into MPP-induced PC12 cellular model for Parkinson's disease. Regen Biomater. 2016;3:299-307.

36. Dagda RK, Zhu J, Chu CT. Mitochondrial kinases in Parkinson's disease: converging insights from neurotoxin and genetic models. Mitochondrion. 2009;9:289-98.

37. Wang G, Pan J, Chen SD. Kinases and kinase signaling pathways: potential therapeutic targets in Parkinson's disease. Progress Neurobiol. 2012;98:207-21.

38. Diegelmann J, Olszak T, Goke B, Blumberg RS, Brand S. A novel role for interleukin-27 (IL-27) as mediator of intestinal epithelial barrier protection mediated via differential signal transducer and activator of transcription (STAT) protein signaling and induction of antibacterial and anti-inflammatory proteins. J Biol Chem. 2012;287:286-98.

39. Son Y, Cheong YK, Kim NH, Chung HT, Kang DG, Pae HO. Mitogen-activated protein kinases and reactive oxygen species: how can ros activate MAPK pathways? J Signal Transduct. 2011;2011:792639.

40. Choi WS, Eom DS, Han BS, Kim WK, Han BH, Choi EJ, et al. Phosphorylation of p38 MAPK induced by oxidative stress is linked to activation of both caspase-8- and -9-mediated apoptotic pathways in dopaminergic neurons. J Biol Chem. 2004;279:20451-60. 
41. Zawada WM, Meintzer MK, Rao P, Marotti J, Wang X, Esplen JE, et al. Inhibitors of p38 MAP kinase increase the survival of transplanted dopamine neurons. Brain Res. 2001;891:185-96

42. Newhouse K, Hsuan SL, Chang SH, Cai B, Wang Y, Xia Z Rotenone-induced apoptosis is mediated by $\mathrm{p} 38$ and JNK MAP kinases in human dopaminergic SHSY5Y cells. Toxicol Sci. 2004;79:137-46.

43. Sadowska AM, Manuel YKB, De Backer WA. Antioxidant and anti-inflammatory efficacy of NAC in the treatment of COPD: discordant in vitro and in vivo doseeffects: a review. Pulm Pharmacol Ther. 2007;20:9-22.

44. Gong X, Duan Y, Zheng J, Wang Y, Wang G, Norgren S, et al. Nephroprotective effects of $\mathrm{N}$-acetylcysteine amide against contrast-induced nephropathy through upregulating thioredoxin-1, inhibiting ASK1/p38MAPK pathway, and suppressing oxidative stress and apoptosis in rats. Oxid Med Cell Longev. 2016;2016:8715185.

45. Pan Z, Niu Y, Liang Y, Zhang X, Dong M. Beta-ecdysterone protects SH-SY5Y cells against 6-hydroxydopamine-induced apoptosis via mitochondria- dependent mechanism: involvement ofp38(MAPK)-p53 signaling pathway. Neurotox Res. 2016:30:453-66.

46. Amaral JD, Xavier JM, Steer CJ, Rodrigues CM. The role of p53 in apoptosis. Discov Med. 2010;9:145-52.

47. Kook YH, Ka M, Um M. Neuroprotective cytokines repress PUMA induction in the 1-methyl-4-phenylpyridinium (MPP $(+))$ model of Parkinson's disease. Biochem Biophys Res Commun. 2011:411:370-4.

48. Kuo HC, Lu CC, Shen CH, Tung SY, Hsieh MC, Lee KC, et al. Hericium erinaceus mycelium and its isolated erinacine A protection from MPTP-induced neurotoxicity through the ER stress, triggering an apoptosis cascade. J Transl Med. 2016;14:78.

49. Wang S, He H, Chen L, Zhang W, Zhang X, Chen J. Protective effects of salidroside in the MPTP/MPP $(+)$-induced model of Parkinson's disease through ROS-NOrelated mitochondrion pathway. Mol Neurobiol. 2015;51:718-28.

50. Er E, Oliver L, Cartron PF, Juin P, Manon S, Vallette FM. Mitochondria as the target of the pro-apoptotic protein Bax. Biochim Biophys Acta. 2006;1757:1301-11.

51. Mullin S, Schapira AH. Pathogenic mechanisms of neurodegeneration in Parkinson disease. Neurol Clin. 2015;33:1-17.

52. Blesa J, Trigo-Damas I, Quiroga-Varela A, Jackson-Lewis VR. Oxidative stress and Parkinson's disease. Front Neuroanat. 2015:9:91.
53. Lopez-Sendon J, Mena MA, de Yebenes JG. Drug-induced parkinsonism. Expert Opin Drug Saf. 2013;12:487-96.

54. Ryan BJ, Hoek S, Fon EA, Wade-Martins R. Mitochondrial dysfunction and mitophagy in Parkinson's: from familial to sporadic disease. Trends Biochem Sci. 2015;40:200-10.

55. Hauser DN, Hastings TG. Mitochondrial dysfunction and oxidative stress in Parkinson's disease and monogenic parkinsonism. Neurobiol Dis. 2013;51:35-42.

56. Gerlach M, Riederer P. Animal models of Parkinson's disease: an empirical comparison with the phenomenology of the disease in man. J Neural Transm. 1996;103:987-1041.

57. Viswanath V, Wu Y, Boonplueang $R$, Chen S, Stevenson FF, Yantiri $F$, et al. Caspase- 9 activation results in downstream caspase- 8 activation and bid cleavage in 1-methyl-4-phenyl-1,2,3,6-tetrahydropyridine-induced Parkinson's disease. J Neurosci. 2001;21:9519-28.

58. Meredith GE, Totterdell S, Beales M, Meshul CK. Impaired glutamate homeostasis and programmed cell death in a chronic MPTP mouse model of Parkinson's disease. Exp Neurol. 2009;219:334-40.

59. Kurkowska-Jastrzebska I, Balkowiec-Iskra E, Ciesielska A, Joniec I, Cudna A, Zaremba $M M$, et al. Decreased inflammation and augmented expression of trophic factors correlate with MOG-induced neuroprotection ofthe injured nigrostriatal system in the murine MPTP model of Parkinson's disease. Int Immunopharmacol. 2009;9:781-91.

60. McNaught KS, Perl DP, Brownell AL, Olanow CW. Systemic exposure to proteasome inhibitors causes a progressive model of Parkinson's disease. Ann Neurol. 2004;56:149-62.

61. Meredith GE, Rademacher DJ. MPTP mouse models of Parkinson's disease: an update. J Parkinsons Dis. 2011;1:19-33.

62. Zhang SM, et al. Intakes of vitamins $E$ and C, carotenoids, vitamin supplements, and PD risk. Neurology. 2002;59:1161-9.

63. Parkinson Study G. Effects of tocopherol and deprenyl on the progression of disability in early Parkinson's disease. New Engl J Med. 1993;328:176-83.

64. Shults CW, Oakes D, Kieburtz K, Beal MF, Haas R, Plumb S, et al. Effects of coenzyme Q10 in early Parkinson disease: evidence of slowing of the functional decline. Arch Neurol. 2002;59:1541-50.

65. Kim GH, Kim JE, Rhie SJ, Yoon S. The role of oxidative stress in neurodegenerative diseases. Exp Neurobiol. 2015;24:325-40. 